\title{
Preterm births and associated factors among mothers who gave birth in Axum and Adwa Town public hospitals, Northern Ethiopia, 2018
}

\author{
Gebrekiros Aregawi ${ }^{1 *}$, Nega Assefa ${ }^{2}$, Firehiwot Mesfin ${ }^{2}$, Fissaha Tekulu ${ }^{3}$, Tesfay Adhena ${ }^{4}$, Mussie Mulugeta $^{4}$ \\ and Guesh Gebreayezgi ${ }^{5}$
}

\begin{abstract}
Objective: The objective of this study was to determine the prevalence and associated factors of preterm births among mothers who gave birth in Axum and Adwa public hospitals, Tigray, North Ethiopia, 2018.

Result: This study showed that $13.3 \%$ from the total 472 mothers gave a preterm birth. Being a rural resident $(A O R=2.13,95 \% \mathrm{Cl}(1.07,4.22)$, short inter pregnancy interval $(A O R=5.4,95 \% \mathrm{Cl}(1.32,22.05)$, previous preterm birth ( $A O R=3.74,95 \% \mathrm{Cl}(1.03,16.34)$, Premature rupture of membrane $(A O R=4.14,95 \% \mathrm{Cl}(1.92,8.89)$, induced onset of labor $(A O R=2.49,95 \% \mathrm{Cl}(1.06,5.85)$ multiple pregnancy $(A O R=5.69,95 \% \mathrm{Cl}(2.27,14.28)$, malaria during pregnancy $(A O R=4.71,95 \% \mathrm{Cl}(1.98,11.23)$, Presence of chronic illness $(A O R=4.55,95 \% \mathrm{Cl}(1.83,11.26)$ were significantly associated with preterm birth.
\end{abstract}

Keywords: Preterm birth, Prevalence, Risk factors, Axum and Adwa, Ethiopia

\section{Introduction}

Preterm birth (PTB) refers to the birth of a baby that occurs before 37 completed weeks of gestation [1]. The complications of preterm birth are the single largest direct cause of neonatal deaths, responsible for $35 \%$ of the world's 3.1 million deaths a year [2].

Preterm birth has many long and short term consequences like cerebral palsy, mental retardation, visual and hearing impairments, learning difficulties, poor health and growth $[3,4]$.

Globally WHO estimates of global rates of preterm births indicate that of the 135 million live births in 2010, 15 million babies were born too early, representing a preterm birth rate of $11.1 \%$ and over $60 \%$ of preterm births occurred in sub-Saharan Africa and South Asia [5].

\footnotetext{
*Correspondence: gkaregawi@gmail.com
}

1 Department of Midwifery, College of Medicine and Health Science, Aksum University, Aksum, Ethiopia

Full list of author information is available at the end of the article
About 350,000 under five children die annually due to the complication of preterm birth in Africa including Ethiopia. And the highest rates of preterm morality are in West Africa, particularly in the countries currently being decimated by Ebola, notably Sierra Leone and Liberia [6].

In the previous studies, previous history of preterm birth was the strongest predictor of risk for subsequent preterm delivery and if these risk factors are not correctly identified and adequately managed, they contribute to the increasing incidence of preterm births. So, Identification and timely referral for further evaluation and management of these risky women during early pregnancy, is important in decreasing the consequences of preterm birth [7].

Developing countries like Ethiopia lacks reliable data on preterm birth depending largely on estimates from delivery records but the records lack consistency and completeness. Despite tremendous improvement in newborn care, prevention of preterm birth has remained largely unaddressed. Therefore, this study has gone a long 
way in providing relevant data regarding the factors associated with preterm birth among women gave birth in Axum and Adwa Town public hospitals.

\section{Main text}

\section{Study design and setting}

Institutional based cross-sectional study was conducted in Axum and Adwa town public hospitals from February 08-March 08, 2017. There are four health centers, two general hospitals and one referral hospital in Axum and Adwa town and all are governmental hospitals.

\section{Sample size and Sampling procedure}

The sample size was determined using single population proportion formula by considering confidence level (95\%), margin of error $=0.04$ and $11.6 \%$ of prevalence taken from the study done in Debre Markos [8]. By adding $10 \%$ non-response rate, the final sample size was 482 . Mothers who gave birth in Axum and Adwa town public hospitals with known LNMP or had ultrasound result during the first trimester of pregnancy were included. Sample sizes were proportionally allocated to each hospital. By using Systematic random sampling method every second mother was recruited into the study.

\section{Data collection tools and techniques}

Face-to-face interviewer administered questionnaires and mother's profile card was used to collect the data from postpartum mothers and gestational age was determined by last normal menstrual period and by early ultrasound check up result.

\section{Data quality control}

Questionnaire was pretested on 5\% of the sample size in suhul shire hospital to ensure its completeness. Data entry was done by two data clerks. Finally, multivariate analysis was run in the binary logistic regression model to control the confounding factors.

\section{Data processing and analysis}

Data was entered in Epi Data 3.1 and exported into SPSS version 22 for analysis. Both bivariable and multivariable logistic regression analysis were carried out to identify factors associated with preterm birth. In bivariate logistic regression analysis, variables with $p$ value less than $20 \%$ were considered into the multivariable analysis. Adjusted odds ratio with a 95\% confidence interval was calculated to see the strength and significant association. Variables having a p-value less than 0.05 in the multivariable logistic regression analysis were considered as significant.

\section{Results}

Socio-demographic characteristics of the respondents

A total of 472 mothers were included in this study with a response rate of $97.9 \%$. The median age of the study participants was 26.00 with interquartile range of \pm 8 . $75.6 \%$ of the study participants were between 20 and 34 years old. Concerning to maternal level of education status of the respondents, $72.8 \%$ of the mothers were attended a formal education (Table 1).

Table 1 Socio-demographic characteristics of women who give birth in Axum and Adwa town public hospitals, Tigray, Northern Ethiopia, February 08-March 08, 2018

\begin{tabular}{|c|c|c|}
\hline Variables & Frequency & Percentage \\
\hline \multicolumn{3}{|l|}{ Maternal age } \\
\hline$\leq 19$ & 42 & 8.9 \\
\hline $20-34$ & 357 & 75.6 \\
\hline$\geq 35$ & 73 & 15.5 \\
\hline \multicolumn{3}{|c|}{ Maternal level of education $(n=472)$} \\
\hline Unable to read and write & 108 & 22.9 \\
\hline Able to read and write & 10 & 4.2 \\
\hline Primary level & 103 & 21.8 \\
\hline Secondary level & 161 & 34.1 \\
\hline College and above & 80 & 16.9 \\
\hline \multicolumn{3}{|c|}{ Maternal marital status ( $n=472)$} \\
\hline Single & 11 & 2.3 \\
\hline Married & 446 & 94.6 \\
\hline Divorced & 11 & 2.3 \\
\hline Widowed & 4 & 0.8 \\
\hline \multicolumn{3}{|c|}{ Maternal occupation ( $n=472$ ) } \\
\hline Housewife & 265 & 56.1 \\
\hline Private employee & 87 & 18.4 \\
\hline Government employee & 84 & 17.8 \\
\hline Merchant & 30 & 6.4 \\
\hline Student & 6 & 1.3 \\
\hline \multicolumn{3}{|l|}{ Maternal religion $(n=472)$} \\
\hline Orthodox & 435 & 92.2 \\
\hline Muslim & 32 & 6.8 \\
\hline Protestant & 3 & 0.6 \\
\hline Catholic & 2 & 0.4 \\
\hline \multicolumn{3}{|l|}{ Ethnicity } \\
\hline Tigray & 459 & 97.2 \\
\hline Amara & 11 & 2.3 \\
\hline Others* & 2 & 0.4 \\
\hline \multicolumn{3}{|l|}{ Residence $(n=472)$} \\
\hline Urban & 308 & 65.3 \\
\hline Rural & 164 & 34.7 \\
\hline
\end{tabular}

Asterisk represent the list of other ethinicities like Oromo, Wolayta, Guragge other than Tigray and Amara 


\section{Obstetrics related information of the mothers}

Out of 472 mothers, 264 (55.9\%) of them were multipara and the rest 208 (44.1\%) mothers were prim Para. Regarding the mode of delivery for recent pregnancy, $367(77.8 \%)$ out of 472 mothers were gave birth via spontaneous vaginal delivery. the rest $32(6.8 \%)$ and 73 (15.5\%) of mothers gave birth via assistance of instrumental and caesarean section, respectively (Table 2).

\section{Health care service use characteristics}

From 472 mothers, 452 (95.8\%) had ANC follow up for the recent pregnancy. Among these mothers who had ANC follow up about 325 (71.9\%) of interviewed mothers had four or more visits.

\section{Medical related information of the mothers}

Out of 472 interviewed mothers, 461 (97.7\%) were tested for HIV and 449 (97.4\%) of them were negative. Concerning to the mothers haemoglobin level checkup, $462(97.9 \%)$ of them were checked for their haemoglobin level (Additional file 1: Table S1).

\section{Prevalence of preterm birth}

Out of 472 mothers, 63 (13.3\%) mothers gave preterm babies. These preterm babies were diagnosed by calculating the gestational age from the last normal menstrual period/using early ultrasound result.

\section{Factors associated with preterm births}

In this study, Mothers who were living in rural area were two times more likely $[(\mathrm{AOR}=2.1(1.05,4.12)]$ to have preterm birth compared to those who live in urban area. Concerning to inter pregnancy interval, mothers with inter pregnancy interval less than 24 months four $[(\mathrm{AOR}=4.24,95 \% \mathrm{CI}(1.15,16.26)]$ times were more likely to give preterm births compared to mothers who had inter pregnancy interval greater. Regarding the previous history of preterm birth, mothers who had history of preterm births were four $[(\mathrm{AOR}=3.74$, $95 \%$ CI $(1.03,16.34)]$ times more likely to give preterm birth compared to mothers who had no previous preterm births.

Coming to the obstetric complications during the pregnancy like PROM, mothers who encountered PROM $[(\mathrm{AOR}=3.76(1.73,8.19)]$ during the pregnancy were almost four times more likely to have preterm birth compared to mothers who had no PROM. Mothers with multiple pregnancy outcomes $[(\mathrm{AOR}=5.59(2.17,14.40)]$ were six times more likely to have preterm birth compared with mothers who gave birth singleton.

Concerning to the medical factors, mothers who had exposed for malaria during pregnancy
Table 2 Obstetrics related information of mothers who gave birth in Axum and Adwa town public hospitals, Tigray, North Ethiopia, and February 08-March 08, 2018

\begin{tabular}{|c|c|c|}
\hline Variables & Frequency & Percentage \\
\hline \multicolumn{3}{|l|}{ Parity $(n=472)$} \\
\hline Multipara & 264 & 55.9 \\
\hline Primipara & 208 & 44.1 \\
\hline \multicolumn{3}{|l|}{ Number of parity } \\
\hline 1 & 39 & 14.8 \\
\hline $2-4$ & 187 & 70.8 \\
\hline$\geq 5$ & 38 & 14.4 \\
\hline \multicolumn{3}{|c|}{ Inter pregnancy interval $(n=264)$} \\
\hline$<24$ months & 38 & 14.4 \\
\hline$\geq 24$ months & 226 & 85.6 \\
\hline \multicolumn{3}{|c|}{ Previous preterm birth $(n=264)$} \\
\hline Yes & 34 & 12.9 \\
\hline No & 230 & 87.1 \\
\hline \multicolumn{3}{|c|}{ History of abortion $(n=472)$} \\
\hline Yes & 71 & 15 \\
\hline No & 401 & 85 \\
\hline \multicolumn{3}{|c|}{ Pregnancy status $(n=472)$} \\
\hline Planned & 434 & 91.9 \\
\hline Unplanned & 38 & 8.1 \\
\hline \multicolumn{3}{|c|}{ Onset of labour $(n=472)$} \\
\hline Spontaneous & 405 & 85.8 \\
\hline Induced & 67 & 14.2 \\
\hline \multicolumn{3}{|l|}{ Mode of delivery } \\
\hline Vaginal delivery & 367 & 77.8 \\
\hline Instrumental & 32 & 6.8 \\
\hline Caesarean section & 73 & 15.4 \\
\hline \multicolumn{3}{|l|}{ PROM $(n=472)$} \\
\hline Yes & 68 & 14.4 \\
\hline No & 404 & 85.6 \\
\hline \multicolumn{3}{|c|}{ History of PIH $(n=472)$} \\
\hline Yes & 38 & 8.1 \\
\hline No & 434 & 91.9 \\
\hline \multicolumn{3}{|c|}{ History of APH $(n=472)$} \\
\hline Yes & 39 & 8.3 \\
\hline No & 433 & 91.7 \\
\hline \multicolumn{3}{|c|}{ Pregnancy type $(n=472)$} \\
\hline Singleton & 434 & 91.9 \\
\hline Multiple & 38 & 8.1 \\
\hline
\end{tabular}

$[(\mathrm{AOR}=5.43(2.19,13.38)]$ and chronic medical disorders $[(\mathrm{AOR}=6.79(2.83,16.26)]$ were seven times more likely to have preterm births than the counterpart (Additional file 2: Table S2).

\section{Discussion}

In this study, the prevalence of preterm births in this study was found to be $13.3 \%$. 
The result of this study was consistent with the study done in Debre Markos (2013) and India (2010) which reported with the prevalence of $11.6 \%$ and $15 \%[8,9]$. This similarity might be due to health care system in our country and service provided for mothers are almost uniform through out the different area of the country.

The finding of this study was higher than the study conducted in Gondar (2012), Iran Asali Hospital (2007) and Egypt (2014) which reported that the prevalence of preterm birth was $4.4 \% 6.3 \%$ and $8.2 \%$ [10-12], respectively. This discrepancy might be due to difference in inclusion and exclusion criteria, study areas and due to difference in health care services provided.

The finding of this study was found to be lower than studies conducted in Nigeria (2010) with the prevalence rate of $24 \%$ [13]. This might be due to the higher rate of multiple gestations in Nigeria, as this cause over distended uterus and can precipitate to preterm birth and multiple gestations is a known predisposing factor for preterm birth.

The finding in this study was also lower than the study done in Kenya (2013), Brazil (2009) and India (2010) which reported that the prevalence were $18.3 \%$ and $21.7 \%$ $[14,15]$. These discrepancies might be due to difference in study areas, methodological differences.

This study showed that residence was associated significantly with preterm birth. This finding was in line with the study done in Bahirdar [16]. This might be due low access of maternal care services and awareness differences of the mothers in the rural area with mother found in the urban area.

Short inter pregnancy ( $<24$ months) was significantly associated with preterm birth. This finding was in consistence with the study conducted in Debre Markos since 2013 [8]. This is a risk factor for preterm birth and it might be due to existence of unidentified factors which precipitating preterm births in mothers with short inter pregnancy interval.

Previous preterm birth was another factor significantly associated with preterm birth found in this study. Mothers who had previous history of preterm births seven times were more likely to have preterm births compared to mothers who had no previous history of preterm births in the subsequent deliveries. This finding was in consistence with the secondary data analysis report of Malawi (2014): [17]. The possible reason might be due to existence of unidentified factors which precipitating preterm births in the subsequent deliveries.

According to this study, mothers who had premature rupture of membranes (PROM) during pregnancy were four times more likely to have preterm birth compared to those had no premature rupture of membrane. This finding was in consistence with findings of cross sectional studies conducted in Debre Markos (2013) and Kenya $(2013)[8,15]$. This may be due to the fact that PROM elevated fetal plasma interleukin- 6 indicating that this fetal response may trigger preterm labor correlated strongly with spontaneous delivery [18].

Multiple gestations were significantly associated with preterm birth in this study. Mothers with multiple pregnancies were almost six times more likely to have preterm birth compared with mothers who gave birth singleton This finding was in line with the finding of study done in Kenya (2013) [15]. This might be due to multiple gestation is associated with uterine over distension and this may result in spontaneous preterm labour and also Multiple pregnancies can stretch the myometrium; this induces the oxytocin receptors, which results in preterm labor and delivery [19].

Chronic medical illnesses are significant variable associated with Preterm birth. Mothers with chronic medical disorders were almost seven times more likely to have preterm births compared to mothers who had not chronic medical disorders. This finding was in consistence with cross sectional study conducted in Debre Markos (2013) [8]. This might be might be due to maternal illnesses can limit or minimize the placental delivery of oxygen and nutrients to the developing fetus in the uterus possibly increase the risk of preeclampsia and, thus, increases the risk preterm birth [20].

Besides to this, mothers who had malaria during their pregnancy were more and mothers who had exposed for malaria during pregnancy were five times were more likely to have preterm births than mothers who had not exposed to malaria during the pregnancy. This result was in line with the study done in Iran (2011-2013) [21]. This might be due to malaria affects placenta and contributes to maternal anaemia and placental parasitemia which leads to preterm labor which in turn result preterm birth [22].

\section{Conclusion}

Residence, short inter pregnancy, previous history of preterm birth, PROM, induced onset of labor, multiple gestation, Presence of chronic medical illness, being exposed for malaria during the pregnancy were statistically significant with preterm birth. Therefore, efforts have to be made to decrease the magnitude of preterm births and further improvements of antenatal care as well as early screening are important recommendations.

\section{Limitation of the study}

Being a cross-sectional study design attempt to our work did not establish the possible temporal relationship between dependent and independent variables. 
Besides, recall bias in finding out the gestational age of pregnant women was not ruled out.

\section{Supplementary information}

Supplementary information accompanies this paper at https://doi. org/10.1186/s13104-019-4650-0.

Additional file 1: Table S1. Medical related information of women who give birth in Axum and Adwa town public hospitals, Tigray, Northern Ethiopia, February 08-March 08, 2018.

Additional file 2: Table S2. Factors associated with preterm births among mothers who gave birth in Axum and Adwa town public hospitals, Tigray, North Ethiopia, February 08-March 08, 2018.

\section{Abbreviations}

ANC: antenatal care; AOR: adjusted odd ratio; APH: ante partum hemorrhage; $\mathrm{Cl}$ : confidence interval; DM: diabetes mellitus; HIV: human immune deficiency virus; PIH: pregnancy induced hypertension; LNMP: last normal menstrual Period; COR: crude odds ratio; PROM: premature rupture of membrane; SPSS: Statistical Package for Social Sciences.

\section{Acknowledgements}

Our gratitude goes to the staffs of Aksum saint Mary hospital, Aksum university referral hospital and Adwa hospital, data collectors, supervisors, study participants, and questionnaire translators into the local languages.

\section{Authors' contributions}

GA initiated the research, wrote the research proposal, conducted the research, did data entry and analysis, and wrote the research and manuscript. NA, FM, FT, TA, MM and GG involved in the write up of the proposal, data analysis, interpretation, and manuscript writing. All authors read and approved the final manuscript.

\section{Funding}

The study was funded by the Ethiopian Ministry of Education and Aksum University that do not involved in the study design, data collection, analysis and interpretation.

\section{Availability of data and materials}

The datasets used and/or analysed during the current study are available from the corresponding author upon reasonable request due to ethical restriction and privacy.

\section{Ethics approval and consent to participate}

Ethical clearance was secured by Haramaya University Institutional Health Research Ethics Review Committee (IHRERC) and official permission was obtained from Aksum and Adwa Town Health Offices and respected health institutions. Informed written consent was also obtained from each participant after the purpose of the study and confidentiality issues were clearly explained.

\section{Consent for publication}

Not applicable.

\section{Competing interests}

The authors declare that they have no competing interests

\section{Author details}

${ }^{1}$ Department of Midwifery, College of Medicine and Health Science, Aksum University, Aksum, Ethiopia. ${ }^{2}$ School of Nursing and Midwifery, College of Health and Medical Sciences, Haramaya University, P. O. Box 235, Harar, Ethiopia. ${ }^{3}$ Department of Midwifery, College of Medicine and Health Sciences, Arba Minch University, Arba Minch, Ethiopia. ${ }^{4}$ Department of Midwifery, College of Health Science, Aksum University, Aksum, Ethiopia. ${ }^{5}$ Department of Public Health, College of Health Science, Aksum University, Aksum, Ethiopia.
Received: 16 August 2019 Accepted: 17 September 2019

Published online: 02 October 2019

\section{References}

1. Lockwood C, Ramin S, Barss V. Overview of preterm labour and delivery. UpToDate. 2011;19(1).

2. Liu L, Johnson H, Cousens S, Perin J, Scott S. Global, regional and national causes of child mortality: an updated systematic analysis. Lancet. 2012.

3. Butler A, Santa, E, Cox T. Institute of Medicine (US) Committee on understanding premature birth and assuring healthy outcomes. Preterm birth: causes, consequences, and prevention. National Academies Press. 2006.

4. WHO (World Health Organization). March of Dimes, the Partnership for Maternal Newborn and Child Health and Save the Children. Born Too Soon: the global action report on preterm births. Geneva: World Health Organization. 2012. www.who.int/pmnch/media/news/2012/20120 4 _borntoosoon-report.pdf. Accessed 26 June 2016.

5. Blencowe H, Cousens S, Oestergaard M, Chou D, Moller AB. National, regional and worldwide estimates of preterm birth rates in the year 2010 with time trends for selected countries since 1990: a systematic analysis. Lancet. 2012. www.sciencedirect.com/science/article/pii/S014067361 2608204. Accessed 26 July 2016.

6. WHO (World Health Organization), UNICEF (United Nations Children's Fund) March of Dimes, the Partnership for Maternal Newborn and Child Health and Save the Children. World prematurity day. 2013. www.who. int/pmnch/media/news/2012/preterm_birth_report/en/index.html. Accessed 26 June 2016.

7. Offiah I, O'donoghue K, Kenny L. Clinical risk factors for preterm birth, preterm birth-mother and child. 2012. http://www.intechopen.com/books /preterm-birth-mother-and-child/clinical-risk-factors-for-preterm-birth. Accessed 26 July 2016.

8. Bekele T, Amanon A, Gebreslasie KZ. Preterm birth and associated factors among mothers who gave birth in Debre Markos Town Health institutions, institutional based cross sectional study. Gynecol Obstet. 2013. https://doi.org/10.4172/2161-0932.1000292.

9. Shubhada A, Kambale SV, Phalke BD. Determinants of Preterm Labour in a Rural Medical College Hospital in Western Maharashtra. Nepal J Obstet Gynaecol. 2013:8(1):31-33.

10. Ayman AS, Abdelwahid A. Rate and risk factors of preterm births in secondary health care facility in Cairo. World J Med Sci. 2015;12(1):09-16.

11. Gebreslasie K. Preterm birth and associated factors among mothers who gave birth in Gondar town health institutions. Adv Nurs. 2016. https://doi. org/10.1155/2016/4703138.

12. Tehranian N, Ranjbar M, Shobeiri F. The prevalence rate and risk factors for preterm delivery in Tehran, Iran. J Midwifery Reprod Health. 2016;4(2):600-4.

13. Kunle-Olowu OE, Peterside $\mathrm{O}$, Adeyemi O. Prevalence and outcome of preterm admissions at the Neonatal Unit of a Tertiary Health Centre in Southern Nigeria. Open J Pediatr. 2014;4:67-75. https://doi.org/10.4236/ ojped.2014.41009.

14. Miranda A, Pinto V, Szwarcwald C, Golub E. Prevalence and correlates of preterm labor among young parturient women attending public hospitals in Brazil. Revista Panamericana de Salud Pública. 2012;32(5):330-4.

15. Wagura P. Prevalence and factors associated with preterm birth at Kenyatta national hospital. University of Nairobi, un published thesis. 2014. http://erepository.uonbi.ac.ke/handle/11295/74707. Accessed July 19 2016.

16. Getachew G, Belaynew W, Teumay A, Mohamed K. Effects of inter pregnancy interval on pre-term birth and associated factors among postpartum mothers who gave birth at Felegehiowt Referral Hospital. World Pharm Pharm Sci. 2015;4(04):12-25.

17. Van Den Broek N, Jean-Baptiste R, Neilson J. Factors associated with preterm, early preterm and late preterm birth in Malawi. PLoS ONE. 2014;9:e90128.

18. Gravett MG, Adams KM, Sadowsky DW. Immunomodulators plus antibiotics delay preterm delivery after experimental intraamniotic infection in a nonhuman primate model. Am J Obstet Gynecol. 2007;197(5):518.

19. Buxton IL, Singer CA, Tichenor JN. Expression of stretch-activated twopore potassium channels in human myometrium in pregnancy and labor. PLoS One. 2010;5(8):e12372. 
20. Behrman R, Butler A. Institute of Medicine (US) Committee on understanding premature birth and assuring healthy outcomes, preterm birth: causes, consequences, and prevention. National Academies Press, 0-30965898-5: 790 pages. http://www.nap.edu/catalog/11622.html. Accessed 18 Mar 2017.

21. Pourfallah M, Albokord M, Saadati N, Cheraghi M. Incidence of preterm labor and its relevant risk factors in mothers referring to health centers in Ahvaz City during 2011-2013. Int J Curr Res Acad Rev. 2015;3:121-6.

22. Rijken MJ, De Livera AM, Lee SJ, Boel ME, Rungwilailaekhiri S, Wiladphaingern J, Paw MK, Pimanpanarak M, Pukrittayakamee S, Simpson JA,
Nosten F, Mcgready R. Quantifying low birth weight, preterm birth and small-for-gestational-age effects of malaria in pregnancy. PLOS ONE. 2014;9(7):e100247.

\section{Publisher's Note}

Springer Nature remains neutral with regard to jurisdictional claims in published maps and institutional affiliations.
Ready to submit your research? Choose BMC and benefit from:

- fast, convenient online submission

- thorough peer review by experienced researchers in your field

- rapid publication on acceptance

- support for research data, including large and complex data types

- gold Open Access which fosters wider collaboration and increased citations

- maximum visibility for your research: over $100 \mathrm{M}$ website views per year

At BMC, research is always in progress.

Learn more biomedcentral.com/submissions 